\title{
¿QUÉ HAY DE NUEVO? LA EDAD MEDIA
}

\author{
Olivier Boulnois \\ doi:10.11144/Javeriana.uph33-67.qnem
}

\section{RESUMEN}

En este trabajo el autor se propone dos objetivos complementarios. En primer lugar, demostrar la actualidad de la Edad Media y, en segundo lugar, la falsa novedad de los Tiempos Modernos. Se trata de mostrar el horizonte medieval de la modernidad y por lo tanto, la falsa disyunción que esta establece entre su propio origen, como ruptura, frente al oscurantismo medieval. El autor analiza varios momentos considerados como indicadores de esta ruptura (el humanismo, la dignidad del hombre y el protestantismo) y varios temas considerados tradicionalmente como modernos (la secularización, el deseo de saber, la concepción del progreso) para mostrar su filiación medieval. Sin embargo, el autor no pretende defender la continuidad histórica dentro de la lógica de la modernidad, sino la posibilidad de una genealogía de los "olvidos" que caracterizan nuestra época, para defender y reconsiderar lo inactual dentro de una nueva definición de lo contemporáneo; y el estudio de la filosofía medieval por ella misma, más allá de su pre-modernidad, en un orden ya postmoderno.

Palabras clave: Edad Media; Renacimiento; Modernidad; posmodernidad; historia de la filosofía

* École Pratique des Hautes Études, París, Francia.

Correo electrónico: boulnois.oliver@gmail.com

La presente traducción al castellano, realizada por Héctor Hernando Salinas Leal, Pontificia Universidad Javeriana (Bogotá-Colombia), procede de un documento inédito en francés. El traductor agradece al autor su autorización para traducir y publicar este texto.

Para citar este artículo: Boulnois, O. (2016). ¿Qué hay de nuevo? La Edad Media. Universitas Philosophica, 33(67), pp. 321-350. ISSN 0120-5323, ISSN en línea: 2346-2426, doi:10.11144/Javeriana.uph33-67.qnem 


\title{
WHAT IS NEW ? THE MIDDLE AGES
}

\author{
Olivier Boulnois
}

\begin{abstract}
In this work, the author has two complementary objectives. Firstly, to demonstrate the contemporaneity of the Middle Ages and secondly, the false novelty of the Modern Times. The author shows the medieval horizon of modernity and, therefore, the false disjunction established between its origin, as rupture and break, considering the Middle Ages as Dark Ages. The author analyses several moments considered as indicating that rupture (the humanism, the dignity of man and Protestantism) and several topics traditionally considered as modern (secularization, the desire of knowledge and the concept of progress), in order to demonstrate their medieval filiations. The author does not pretend to defend the historical continuity within the logic of modernity, but the possibility of a genealogy of "oblivions" characterizing our age, in order to defend and reconsider the non- contemporary within a new definition of the contemporary and the study of medieval philosophy for herself, beyond her pre-modernity, in a post-modern order.
\end{abstract}

Key words: Middle Ages; Renaissance; Modern Times; post-modernism; history of philosophy 
Conocemos la PRegunta de Heidegger: «¿Qué significa pensar?» («Qu’appelle-t-on penser?», «Was heisst denken?») Es decir, para ser más precisos: ¿qué llama al pensamiento? ¿Qué nos llama a pensar? Yo agregaría: ¿qué nos invita a pensar hoy? ¿Cuál es la urgencia de nuestro pensamiento actualmente? La respuesta más evidente parece contenida en la pregunta: tal vez se trate de la época presente. El fin de las ideologías nos ordenaría pensar lo contemporáneo. Habría que tener un pensamiento a la medida de lo actual, un pensamiento moderno.

Y, sin embargo, podría ser que el llamado a la modernidad sea vacío, tan indeterminado como el aquí y el ahora de la certeza sensible. Podría ser que la modernidad no se encuentre allí donde se la espera, en el presente y en lo actual, sino que exija una consideración más seria del pasado y de lo inactual.

Aquí quisiera proponer que nada es más urgente que un estudio serio de la filosofía medieval. Y esto por dos razones: porque lo intempestivo es quizá más necesario que lo contemporáneo. Y, también, porque no podemos ignorar el pasado. Sabemos que aquellos que rechazan el pasado están condenados a repetirlo.

Ahora bien, toda nuestra tradición cultural y filosófica reposa sobre la idea de una continuidad entre nuestra cultura, la cultura europea moderna y la cultura antigua que se desarrolló alrededor de la cuenca del Mediterráneo hace dos o tres mil años. Idea según la cual los logros de la cultura clásica aún son válidos hoy. Aún se enseña la filosofía dialogando con Platón y Aristóteles como lo hacemos con nuestros contemporáneos. Charles Péguy decía que "aún hoy, Homero es nuevo". Pero esta continuidad no va de suyo. Por el contrario, ella es el resultado de un esfuerzo permanente por reapropiarnos lo antiguo. Y, sin embargo, supone la ficción de un contacto inmediato entre nuestras fuentes y nosotros mismos. Sugiere que no hay nada entre el origen y nosotros. Nos desvía de la edad intermedia, de la Edad Media. Hace como si la Edad Media no hubiera contribuido en nada a hacer de nosotros lo que somos: modernos.

Aquí quisiera sostener la tesis contraria: de un lado, la Edad Media constituye un aspecto esencial de nuestra identidad moderna, simplemente porque es gracias a ella que - al menos en filosofía - nos hemos apropiado de lo antiguo. De otro lado, precisamente a causa del esquema moderno, la Edad Media constituye un continente olvidado, inexplorado. Hasta ahora comenzamos a ver cómo ha contribuido a nuestra identidad moderna, a nuestra modernidad. Estudiar la Edad Media es, pues, una promesa en el porvenir. 
En primer lugar, hay que formular algunas observaciones sobre la noción de modernidad y sugerir que la Edad Media no es menos moderna que los Tiempos Modernos, sino que ella lo es de otro modo. Mi propósito puede así entenderse como un contrapunto al debate que se extiende de Hegel hasta el gran libro de H. Blumenberg, La legitimación de la Edad Moderna (1988), y como una contribución a las discusiones de fin del siglo XX sobre el humanismo, el progreso y la modernidad. Aprovecharé la ocasión para deshacer un cierto número de mitos historiográficos.

1. ¿Qué es la modernidad?

¿QUé ES SER MODERNO? El TÉRMINO “MODERNo" remite en primer lugar al observador y significa la época contemporánea. En latín, los moderni son simplemente los autores más recientes, los más próximos de quien habla. La modernidad es pues en primer lugar el término abstracto que responde a ese punto de referencia concreto. En el siglo XIX, Chateaubriand utiliza le término en ese sentido, por oposición a "antigüedad", para evocar con un matiz peyorativo la vulgaridad de los tiempos modernos ${ }^{1}$.

En segundo lugar, la modernidad designa un término absoluto, una actitud estética y ética, una manera de ser: la búsqueda de lo nuevo como fin en sí. Baudelaire (1976), que deseaba hundirse en el infinito "para encontrar lo nuevo" llamaba así a "una teoría racional e histórica de lo bello único y absoluto" (II, p. 685). La modernidad es la manera en la que el espíritu y sus obras se dicen en la historia. "La modernidad es lo transitorio, lo fugitivo, lo contingente, la mitad del arte, cuya otra mitad es lo eterno y lo inmutable” (Baudelaire, 1976, II, p. 695). La modernidad ya no se opone a las otras épocas, como los Tiempos Modernos a la Edad Media, sino que se convierte en una actitud estética, lo que implica que cada momento de la historia tiene su propia forma de modernidad, su manera propia de percibir la escondida belleza del mundo. Ella se opone a una estética de lo ideal, de la forma inmutable y busca la belleza en lo múltiple y en el devenir.

1 "La vulgarité, la modernité de la douane et du passeport, contrastaient avec l'orage, la porte gothique, le son du cor et le bruit du torrent" (Chateaubriand, 1860, V, p. 527). 
En un tercer momento, el término se convierte en un valor que define un objetivo de la acción estética y ética. La frase de Rimbaud en Una temporada en el infierno "hay que ser resueltamente moderno", será retomada como lema por todas las vanguardias del siglo XX: el surrealismo, el marxismo y el existencialismo. En Rimbaud, la expresión precisamente no tiene un sentido humanista (como en Renan), no implica ninguna creencia en el progreso: tal hipótesis había sido eliminada en un pasaje anterior del poema. No era un eslogan colectivo, sino el grito de un poeta que penetra más allá de todo arte poético. No se trata de la orden de situarse en las primeras filas del combate histórico, sino de la necesidad de afrontar solo el destino, en una soledad trágica, incluso sin la protección de una poética ya explorada. Pero, para las "vanguardias" que he mencionado, ser moderno es buscar siempre más modernidad, querer una modernización continua, cuando no la revolución permanente. El progreso se convierte en su propio fin. La modernidad se opone a la tradición. Ella es la coincidencia entre un período y una actitud mental, una categoría general y un imperativo cultural. Ella implica la eliminación de todo lo que obstaculiza su propia realización, en particular las instituciones del pasado, fatalmente superadas. La paradoja consiste entonces en que la modernidad se convierte en una exigencia permanente de cambio que hace del cambio un valor estable, es decir, se convierte en la tradición de lo nuevo. Así expresada, la modernidad conduce a la colusión de las vanguardias artísticas, políticas, filosóficas: ser moderno es, en estética, ser innovador, pero también encontrarse en la punta del progreso histórico y, finalmente, ser el intelectual precursor al servicio de las masas laboriosas. La revista fundada por Sartre se llamaba, por lo demás, Los tiempos modernos (como el filme de Charlie Chaplin). La orden puede por tanto servir para descalificar las estéticas, las prácticas y las doctrinas calificadas de reaccionarias y volverse un eslogan terrorista (es lo que ha mostrado admirablemente Milan Kundera en La vida está en otra parte). El término de la evolución es aquí el nihilismo; una suerte de nihilismo obligatorio, en el que nada resiste a la transvaloración de los valores: ¿ Todo lo pasado (passé) no está acaso ya superado (dépassé)? El concepto de modernidad implica pues la identificación de dos caracteres: uno, la modernidad es el carácter de lo que es moderno, es decir, de lo que es contemporáneo a nosotros; dos, la modernidad designa un período más fiel a este ideal: el período moderno. Con los 
Tiempos Modernos, el hombre es apremiado a pensar de una manera nueva, conforme a la época, siempre más moderna.

Ahora bien, ¿La modernidad solo es un eslogan ideológico o tiene un fundamento conceptual que la hace legítima? ¿Hay un ideal de los Tiempos Modernos, un ideal que habría sido puesto al día por el progreso de la historia, pero que precisamente no estaría sometido a la ley del progreso, ni expiraría con el tiempo? ¿Hay un concepto, una estructura que escape al frenesí destructor de la modernización? Tal es el desafío que enfrentó $\mathrm{H}$. Blumenberg en su gran obra. ¿Cuál puede ser el fundamento conceptual de tal interpretación? Bajo formas teóricas diversas, el concepto de modernidad supone que la esencia de lo moderno (la modernidad) se cumple por excelencia en los tiempos modernos, y que estos constituyen la cima de la historia, un período que aún ofrece toda su legitimidad a las empresas intelectuales actuales (contemporáneas). En suma, esto implica que hayamos entrado en la modernidad con los Tiempos Modernos y que aún no hayamos salido de ellos.

El concepto de modernidad, tal como lo desarrollan Baudelaire y Rimbaud, es estético, pero se apoya sobre los análisis filosóficos del pensamiento kantiano. En el opúsculo ¿Qué es la Ilustración? conocemos la respuesta de Kant: "La salida del hombre de su minoría de edad, de la cual él mismo es responsable (...). Ten el valor de hacer uso de tu propio entendimiento, tal es la divisa de la Ilustración". Es, pues, con la reivindicación de la autonomía del pensamiento que el hombre accede a su mayoría de edad, es decir, finalmente, a su propia esencia. Y, aún allí, el concepto está ligado a un período: se trata de una época precisa, el siglo XVIII de Federico II, que hizo posible su cumplimiento. La modernidad está ligada a una filosofía de la historia; esta supone una noción de progreso, el cumplimiento de este progreso en una cierta esencia (la capacidad de pensar por sí mismo), y un período en el que comienza este cumplimiento (Foucault).

Una filosofía de la historia análoga es desarrollada por Hegel, centrada sobre la idea de que la razón solo accede a sí misma en una teoría del sujeto. La gran ruptura se encuentra por tanto en Descartes, en quien el yo y su conciencia de existir forman el punto de Arquímedes para la conquista del mundo. Para Hegel, la modernidad remite a la interpretación del hombre como sujeto libre. Esta lectura se apoya sobre un substrato metafísico coherente, el primado de la subjetividad: "Tenemos, por lo tanto, a decir verdad, dos Ideas: la idea subjetiva en tanto 
que saber y la idea substancial, concreta; el desarrollo, la elaboración de este principio, a fin de que llegue a la conciencia del pensamiento, constituye el interés de la filosofía moderna. (...) Saber lo que es libre por sí, tal es el principio de la filosofía moderna” (Hegel, 1954, p. 220). De allí la conclusión de Hegel (1954): "En conjunto, tenemos pues dos filosofías: $1^{\circ}$ ) la filosofía griega; $2^{\circ}$ ) la filosofía alemana” (p.221). El pensamiento griego concibió la idea de la libertad, el pensamiento moderno (cartesiano, y luego esencialmente alemán) la realizó. Esta doble tesis interpreta la filosofía como orientada hacia el progreso, pero entre los dos momentos-faro, ella excluye ipso facto la existencia de una filosofía medieval. Muchos historiadores de la filosofía le han seguido el paso.

\section{2. ¿Novedad de los Tiempos Modernos?}

LA PRETENSIÓN DE LA MODERNIDAD está ligada a la idea de «hacer época», de introducir una ruptura con respecto al orden anterior, inmediatamente calificado de tradicional. Pero, ¿qué hace época con los Tiempos Modernos?

$\mathrm{Al}$ respecto, observemos, antes que nada, que el Renacimiento y la Edad Media son conceptos correlativos. Primero, históricamente correlativos. Se atribuye a un tal A. G. Bussi, desde 1469, la invención del término "media tempestas" (edad intermedia), pero, entonces, el término solo designa el período reciente. Este solo toma su sentido conceptual al tener por contrario el término "rinascita" (renacimiento), término empleado por Vasari en su Vidas de los más excelentes pintores, de 1550. El presente aparece, entonces, como el regreso a una Antigüedad luminosa, después de un período sombrío y bárbaro. Así, el concepto "reaccionario" (en su sentido propio y no político) de Renacimiento es por tanto una autolegitimación de los artistas y letrados del siglo XVI. Por su parte, Francis Bacon elaborará la teoría de la Edad Media como período de ignorancia, opuesto a los Tiempos Modernos.

Segundo, Edad Media y Renacimiento son conceptos lógicamente correlativos. Observemos que esta periodización solo tiene sentido para el mundo occidental latino. La idea de una Edad Media japonesa o amerindia parece absurda. Tampoco tiene sentido hablar de una Edad Media árabe o bizantina. No se trata de afirmar que todas estas culturas hayan sido necesariamente menos ricas que la cultura medieval durante el mismo período, sino de observar que ellas 
precisamente no conocieron el fenómeno del Renacimiento. Ahora bien, no hay "renacimiento" de las letras y de las artes, incluso de la razón, si no se postula ipso facto un período oscuro, una ruptura en la transmisión de la cultura, de la razón y de la libertad, o un obstáculo a su expansión. Y esto tanto más que parece difícil explicar el retraso en el desarrollo de esas facultades profundamente idénticas en la naturaleza del hombre. ¿Por qué la luz natural habría esperado la época de la Ilustración para realizarse? ¿Qué impide a la razón expresarse como racionalismo? Hay entonces que postular un freno, una suerte de principio de retención que impide la realización del progreso: este será la Edad $\mathrm{Media}^{2}$. Es por ello que el renacimiento (real) del siglo XVI nace en el acto mismo de autocelebrarse; él tiene la necesidad de postular una (mítica) edad sombría, una era intermedia que separa en lugar de unir: el medium aevum. En consecuencia, los Tiempos Modernos tienen la necesidad conceptual de la Edad Media para ser ellos mismos. Como lo observa Blumenberg, la modernidad nace de un acto performativo: la actitud que afirma que jamás hay que conformarse con la cultura y la ciencia establecidas, y que, por lo tanto, implícitamente, hay que ser moderno constituye al mismo tiempo el acta de nacimiento de los Tiempos Modernos.

Sin embargo, el renacimiento de las letras griegas es la realización de la Edad Media, que no ha sido más que una larga serie de renacimientos: el carolingio, el del siglo XII, el del siglo XIII, que desemboca en el florecimiento (que algunos historiadores han llamado curiosamente el otoño) del Trecento y del Quattrocento italiano (Ladner, 1982). Para Blumenberg, esta explicación es aún una proyección anacrónica de los Tiempos Modernos en busca de precursores. Puede estimarse, por el contrario, que este diagnóstico de los historiadores es una suerte de regreso de lo reprimido (retour du refoulé). Hoy ya no es posible ignorar todos los trabajos de historia material y cuantitativa de larga duración, según los cuales la Edad Media fue para Occidente un largo período de crecimiento demográfico, de lenta mutación en los dominios técnico y social, de acumulación de riquezas -una suerte de acumulación progresiva de capital. En el dominio intelectual, se puede ir más lejos y recordar que jamás hay origen puro: lo propio de Europa ha sido siempre de reenergizarse (se ressourcer), es decir, de tomar un nuevo impulso 
por le conocimiento de otras fuentes, de reanimarse gracias a otras culturas (griegas, judías y árabes). Así entendido, el Renacimiento del siglo XVI solo es el resultado y el logro del proyecto medieval. Pero, mientras la Edad Media reencontró progresivamente todas las obras de Aristóteles y algunos diálogos de Platón, y se renovó así intelectualmente durante todo su curso al reencontrar sus fuentes griegas, el Renacimiento se realizó cuando lo esencial de las fuentes griegas estuvo por fin disponible con la edición de todos los diálogos de Platón y la traducción latina de las Enéadas de Plotino por Marsilio Ficino en 1492. El Renacimiento completa y lleva a término el proyecto intelectual de la Edad Media. Entre los dos términos correlativos hay tanto de continuidad como de ruptura.

Puede incluso negarse la discontinuidad: afirmar que el Renacimiento comienza en la Edad Media. En cierto sentido, nuestra explicación admite esta respuesta. Y todos los trabajos históricos recientes no dejan de reestablecer continuidades allí donde los autores del siglo XVI creían realizar una Instauratio Magna (una gran renovación, según la formula de Francis Bacon). Pero en otro sentido, incluso nuestra interpretación aún supone una discontinuidad radical, en la medida en que la nueva integración del origen exterior (griego) induce para el mundo latino una situación radicalmente nueva. "Entre la caída de Granada y la reconquista del Aristóteles griego, hay un punto común: el árabe, el hombre y la lengua, son expulsados del patrimonio. El movimiento no se detiene allí. La expulsión de los judíos amenaza a Toledo. Ya no hay deuda exterior. Bizancio está muerto y Grecia está allí, intacta" (de Libera, 1993, p. 487). Ahora, Grecia ha sido completamente integrada, ya no es un extraño lejano y pasado: puede tenerse la ilusión de que renace. El Renacimiento puede llamarse así porque accede directamente a todo el pensamiento antiguo y se inspira en él sin reserva. Ahora bien, precisamente esta inmediatez (que paradójicamente es alcanzada al término de numerosas mediaciones) constituye una situación nueva, desconocida en la Edad Media. En Italia se acompaña del orgullo nacional de revivir la grandeza de Roma. Por el contrario, la Edad Media solo accede al origen griego gracias a un conjunto de mediaciones complejas (en especial las traducciones árabes y hebraicas). Rechazar la Edad Media es pasar por alto mil años de cultura, ignorar el aporte de la cultura árabe, del judaísmo, de los teólogos. Se trataría de un olvido de diez siglos, el paréntesis más grande en la historia del pensamiento. 
Así, la pretendida ruptura de los Tiempos Modernos sigue siendo un enigma. Antes de Blumenberg fueron propuestas muchas explicaciones. Se ha atribuido esta supuesta ruptura al humanismo, al descubrimiento de la dignidad del hombre o, finalmente, al protestantismo.

\section{1 ¿EL HUMANISMO?}

LA RUPtURA INAUgURAda POR EL Renacimiento puede leerse como una ruptura interna de la escolástica. Si se entiende por escolástica, en el sentido propio y conforme a la etimología (Quinto, 2001), el conjunto de doctrinas enseñadas en las escuelas universitarias, que reposa sobre una argumentación lógica y se caracteriza por la forma de la quaestio; habría sido esta estructura portadora del pensamiento escolástico la que habría estallado bajo la presión contradictoria de distintas fuerzas interiores, es decir: "al dudar de la empresa en su conjunto a causa del cambio de racionalidad teológica (...) se produjo un repliegue de la teología (y de la filosofía) sobre ella misma” (Bianchi \& Randi, 1993, p. 143). Cuando la ciencia dominante, la teología, se replegó sobre sí misma, dejó de cubrir la empresa filosófica, y esta, a su vez, se replegó también sobre sí misma. Se deshizo, para ser más precisos, el triángulo formado por la teología, la lógica y el humanismo letrado. Mientras que el siglo XV vio desarrollarse una verdadera "teología lógica”, la lógica deja de informar la teología en el siglo XVI. De repente, ella es el objeto de todos los ataques del humanismo, unánimemente criticada por Erasmo, Lutero, Tomás Moro y Rabelais. Desde entonces, la filosofía se desarrolla sobre bases literarias, bajo la forma de tratados: ella deja de arriesgarse en una argumentación dialéctica, sometida a las estrictas reglas de la lógica.

De lo anterior, pueden encontrarse causas institucionales: el desplazamiento del saber de la universidad a las cortes (principescas o, por lo demás, pontificales). Al respecto, de Libera (1993) afirma: "durante el siglo XV, la política se apodera de la Universidad y la Universidad de la política. (...) El filósofo renaciente se opone al profesor" (pp. 474, 486). El desarrollo de una filosofía fuera de la universidad es uno de los rasgos más notables de la filosofía del Renacimiento, como de la época Moderna (pensemos en Descartes o Spinoza, por ejemplo). El eclipse de la escolástica es, en primer lugar, la salida de los filósofos fuera de la Escuela.

Pero detrás de esta problemática se esconde un anacronismo de los historiadores. Este atribuye al concepto de humanismo un sentido distinto al que tenía 
en el siglo XVI. Se trata del contrasentido que se encuentra, por ejemplo, en la obra de Sartre cuando afirma que "el existencialismo es un humanismo". En realidad, la misma palabra "humanismo" (atestiguada en el siglo XVIII con el sentido de "filantropía"), solo recibió este nuevo sentido en el siglo XIX, bajo el impulso de E. Renan (1949), para designar "el culto de todo lo que es del hombre" (III, p. 809) $)^{3}$, en una formula que conduce indistintamente, pero de una manera muy reveladora, a todo lo que es propio del hombre y a todos los productos de la actividad humana. Ahora bien, los antiguos hablaban de "bumanitas", de humanidades (en plural), para designar las disciplinas literarias. El término italiano "umanista", forjado en el siglo XVI sobre el modelo de "artista" (estudiantes de artes, es decir, de gramática y lógica) o "jurista” (estudiantes de derecho) designa simplemente el estudiante o el maestro de retórica. Pero esta disciplina existía desde la Edad Media. Al aclimatar el sentido de "humanismo", al final del siglo XIX, E. Renan y los historiadores del Renacimiento cedieron a un doble prejuicio ideológico: reducir el estudio de esos estudios literarios al Renacimiento y al "descubrimiento" de la nobleza del hombre (Boulnois, 1993, pp. 293-295).

Ahora bien, tanto el uno como el otro son falsos, pues existe una forma de humanismo medieval. La obra de Petrarca (siglo XIV) ofrece una prueba manifiesta: fuera de la enseñanza escolástica, el culto de las letras existe; es puesto al servicio de la formación ética y de la fe cristiana (Petrarca, 2000; Boulnois, 2000). San Bernardo, feroz adversario de la escolástica, pero admirable estilista, es otro ejemplo. Inversamente, el humanismo no constituye la totalidad de la enseñanza durante el Renacimiento. La jurisprudencia, la medicina, la teología y la filosofía no se reducen a ella. Esta última disciplina constituye una literatura abundante, mal evaluada por los historiadores víctimas del mismo prejuicio, que a menudo solo estudian del Renacimiento, el humanismo, y solo ven en la escolástica de ese período, los desafortunados, inútiles y obstinados restos de viejas

3 Escrito hacia 1848 y publicado en 1890: "la religión del porvenir será el puro 'humanismo', es decir, el culto de todo lo que es del hombre”. Observemos, por lo demás, que el término no califica aquí al Renacimiento, sino al ideal del hombre en el porvenir. Parece transcribir un germanismo, empleado (a partir de 1808) para defender la cultura clásica en el programa universitario. Para Renan, la toma de conciencia de la humanidad tuvo lugar en 1789, con la Revolución Francesa. Señalemos que este concepto de progreso (occidental) tiene por correlato el racismo: "se ha constatado la desigualdad de las razas" (Renan, 1949, III, p. 724), y que un día llegará a su término: "entonces será el tiempo de detenerse" (prefacio de 1890, p. 723). 
tradiciones, de antemano eliminados por el sentido de la historia y, por lo tanto, legítimamente despreciables. (Ahora bien, esta enseñanza sobrevivió, con una riqueza desigual, en la escolástica moderna cuyo ejemplo más importante es la escolástica jesuita (Schmutz, 2000).

\section{2 ¿LA DIGNIDAD DEL HOMBRE?}

El SEGUNDO PUNTO EVOCADO POR RENAN NOS CONDUCE a la otra "fuente" de la ruptura de los Tiempos Modernos: la afirmación de la dignidad del hombre.

La historia de la estética ofrece un bello ejemplo de esta interpretación. A menudo se ha dicho que la pintura del Renacimiento no dirigía la mirada de los hombres hacia el cielo, sino hacia la tierra. Los pintores del Renacimiento habrían escogido pintar lo humano en lugar de lo divino. Esta interpretación remonta al menos hasta la estética de Hegel y encuentra también su expresión en ciertos historiadores: "De ahora en adelante el arte se consagrará al hombre y no a Dios" (Charles, 1996, p. 818c). Así, el célebre dibujo de Leonardo Da Vinci, que inscribe el cuerpo humano en un círculo y un cuadrado, y mide todas sus proporciones, pudo ser interpretado como una exaltación del poder humano (es en ese sentido, por lo demás, que se convirtió en la insignia de Manpower). Sin embargo, se trata simplemente de una tentativa de solución del antiguo problema del canon y de las proporciones humanas (de los que se encuentran algunas formulaciones medievales en el Album de Villard de Honnecourt). Es inútil recordar, por lo demás, la importancia de los temas teológicos en la obra de Leonardo. La ruptura entre la estética moderna y la estética medieval es mucho más sutil.

La afirmación de la dignidad del hombre, lejos de ser una novedad del siglo $\mathrm{XVI}$, es tan antigua como el pensamiento griego, luego retomada por la teología cristiana, ilustrada por la patrística y la teología medieval (Boulnois, 1993, pp. 316-323). En realidad, el violento debate alrededor de la interpretación de Pico de la Mirandola nos enseña más sobre los supuestos ideológicos de sus intérpretes que sobre las obras mismas. A propósito de la pretendida ruptura instaurada por Pico, se conocen interpretaciones racionalistas, marxistas y existencialistas. Pero, Pico es, finalmente, bastante clásico en ese punto. En su Discurso sobre la dignidad del hombre, entrelaza innumerables citaciones filosóficas, patrísticas y escolásticas. Pico de la Mirandola es por lo demás tanto un escolástico como un humanista. Se apoya sobre una lectura profunda de los más grandes teólogos 
escolásticos (Alberto Magno, Tomás de Aquino, Duns Escoto, etc., con la excepción de Guillermo de Ockham, es decir, una vez más, de la lógica). En este sentido, el humanismo no era en absoluto patrimonio exclusivo de los humanistas en sentido estricto, es decir de los eruditos en las "bumaniores litterae" (Garin, 1938; de Lubac, 1974). Sobre este punto, pues, la alternativa entre escolástica y humanismo es falsa. Incluso si la desprofesionalización y la politización de la filosofía caracterizan el fin de la Edad Media, no hubo un derrumbe interno de la escolástica. La idea de que el humanismo sea un movimiento filosófico fundamentalmente nuevo reposa sobre un contrasentido moderno.

La dignidad humana se arraiga, según la Biblia, en su creación "a imagen y semejanza de Dios” (Gén. 1:26). Agustín distingue estos dos términos: la imagen de Dios describe su esencia y no puede perderse. Pero la semejanza se pierde por el pecado y se restituye por la gracia. Allí encontramos una descripción histórica y dramática de la humanidad orientada hacia una doctrina de la salvación. Los historiadores vacilan acerca del significado de este análisis. Unos ponen el acento sobre el origen y ven entonces una depreciación de la dignidad humana. Ciertamente, el opúsculo de Lotario de Conti (futuro Inocencio III) De miseria humanae conditionis (1195-1196), ofrece un cuadro penetrante de las debilidades y del infortunio del hombre (Faye, 2002). Sin embargo, otros ponen el acento sobre el hecho de que ese relato sobre los orígenes está destinado a ser más que compensado por una espera en el fin último, puesto que la dignidad prometida es superior a la dignidad de la sola naturaleza creada. El fondo del problema es otro: se trata de preguntarse cuál análisis da mejor cuenta del fenómeno, el que describe, por un análisis histórico, un estado de la naturaleza humana, el estado de la naturaleza caída, llamado a devenir estado de naturaleza salvada; o el que describe, por un análisis conceptual, la esencia del hombre. Esta definición conceptual distinguirá la parte esencial de su parte perfectible según otros parámetros. Tras el redescubrimiento de Aristóteles, al definir al hombre como animal racional, la filosofía da a esta forma general un contenido conceptual que le permite pensar la unidad de la substancia, su inmortalidad, su sociabilidad y de teorizar su libertad radical.

La superposición de estas dos rejillas de lectura es tan antigua como la conjunción de la filosofía y la teología. Sin embargo, ella conduce a asunciones propiamente "modernas" desde el siglo XIII. Los maestros de la facultad de artes 
subrayan que la dignidad del hombre coincide con la perfectio hominis, una noción extraída del prólogo de Averroes a su comentario a la Física de Aristóteles (en traducción latina): la perfección del hombre consiste en la adquisición de las ciencias teóricas, en ella consiste la felicidad, y por eso aquellos que no tienen aptitud para la ciencia no son hombres sino de manera equívoca (Averroes, 1572, $f^{\circ} 1$ ). Armonizando estas observaciones a partir deAristóteles (en la Ética a Nicómaco X), sobre la vida del pensamiento, los maestros de artes muestran que el hombre encuentra su felicidad más alta en la vida virtuosa y la actividad del intelecto. La gran diferencia entre la solución cristiana y la solución filosófica consiste, simplemente, en que la beatitud cristiana es prometida a todos los hombres que aceptan la revelación, mientras que la felicidad filosófica es alcanzada por los sabios, es decir, por un pequeño número, después de numerosos esfuerzos y con grandes riesgos de error, como lo decía Maimónides citado por santo Tomás. La humanidad del hombre consiste en el pensamiento. Puesto que la esencia del hombre es ser solamente intelecto, Tomás de Aquino se propone demostrar que el alma es inmortal y puede subsistir al cuerpo. Otros, en el siglo XIV, como Ockham o Buridán, en el mundo latino, o Gersónides, en el mundo judío provenzal, niegan toda validez a las pruebas de la inmortalidad del alma. En el Renacimiento, Pietro Pomponazzi también negará toda validez a tal prueba. De allí se deriva que el nivel de beatitud que el alma es capaz de alcanzar es proporcional al grado de ciencia adquirido aquí abajo, in statu isto — una tesis familiar a todos los lectores de Spinoza, en especial en Ética (V, 29, p. 37)4.

¿Se sigue, pues, que afirmar la perfección o la dignidad del hombre sería "resueltamente moderno"? Esto sería olvidar que el desarrollo de una dignidad filosófica está encuadrado por una reflexión teológica, muchísimo más rica que la del Renacimiento, sobre la dignidad del hombre en su destino sobrenatural. La variación del sujeto humanista tiene una estructura y un modelo: el hombre es a imagen de Dios. Es un singular universal, un singular cuya libertad lo hace universal. En consecuencia, la transcendencia del hombre es la trascendencia de la libertad.

La célebre prosopopeya del Discurso sobre la Dignidad del hombre ofrece la prueba: 
Yo no te di ni lugar determinado, ni rostro propio, ni don particular, oh Adán, con el fin de que tu lugar, tu rostro y tus dones, los quieras, los conquistes y los poseas por ti mismo. La naturaleza guarda otras especies bajo leyes establecidas por mí. Pero tú, a quien no limita nada, por tu propio arbitrio, entre las manos del cual te puse, tú te defines a ti mismo. Yo te puse en medio del mundo, con el fin de que puedas contemplar mejor alrededor de ti lo que el mundo contiene. No te hice ni celeste ni terrestre, ni mortal ni inmortal, con el fin de que, soberano de ti mismo, acabes tu propia forma libremente, a la manera de un pintor o de un escultor. Tú podrás degenerar en formas inferiores como las de las bestias, o, regenerado, alcanzar las formas superiores, que son divinas. (Pico de la Mirandola, 1993, pp. 5-7)

Esta soberbia descripción envuelve, a través de su elocuencia literaria ("humanista"), muchas proposiciones metafísicas ("escolásticas”): todas las criaturas tienen una especie o una esencia finita; cada especie finita es imagen de una idea finita en Dios; pero el hombre no es una criatura como las otras, pues su modelo no es una idea en Dios, sino Dios mismo. Es, pues, precisamente por la infinidad de su libertad que el hombre es imagen del Dios infinito. Ya que por su libertad el hombre puede identificarse con todas las naturalezas que él deviene, así como Dios es idéntico a todas las esencias que concibe. La libertad del hombre hace de él, en potencia, toda naturaleza. Él es, pues, infinito, y puede elevarse en toda la extensión de los trascendentales: del bien más bajo (el mal) hasta el soberano bien. Así, la infinidad del hombre trascenderá todo estado singular y toda intelectualidad particular. El hombre indefinible es la imagen del Dios infinito.

En su formulación nueva y vibrante, este texto entrelaza aquí tres tesis perfectamente clásicas en la Edad Media: el hombre es imagen de Dios (unanimidad bíblica, patrística y medieval); la esencia del hombre se caracteriza más por la libertad que por el intelecto (Gregorio de Nisa, Bernardo de Claraval, Duns Escoto, Ockham); el hombre no tiene una naturaleza con el fin de poder revestirlas todas (Eckhart y Nicolás de Cusa). Como puede verse, Pico de la Mirandola está lejos de la imagen "nihilista" divulgada por ciertos intérpretes. Él no comprende la trascendencia del hombre en una definición puramente antropológica. La libertad del hombre tiene un modelo, incluso si este no le asigna ningún contenido. La libertad es, en efecto, la imagen de Dios, y nada más que de Dios. Pico no se compromete pues con un prometeísmo escéptico o cínico, sino 
que retiene una definición epimeteica de la dignidad del hombre: Prometeo solo es un dios entre otros, solo Epimeteo es todos los hombres. La exaltación de la dignidad del hombre, y precisamente de esta que confiere la libertad, no sería por tanto posible sin la reflexión medieval sobre la libertad.

\section{3 ¿EL PROTESTANTISMO?}

Parece más prudente distinguir y ordenar los problemas. Cada pregunta, cada disciplina avanza a su propio paso. La filosofía no evoluciona al mismo ritmo que la rotación trienal, el capitalismo, las artes o las letras. Ahora bien, en el elemento del pensamiento, una de las principales transformaciones de su cuadro, incluso la ruptura del cuadro que permitía el ejercicio de la filosofía, fue constituida por el advenimiento del protestantismo.

La teología medieval se apoyaba sobre la armonía entre el conocimiento natural de Dios y la fe, o el deseo natural de Dios y la beatitud del creyente. Para la mayoría de los medievales, después de Platón, Aristóteles y Cicerón, el deseo de la felicidad encuentra naturalmente su cumplimiento en la imitación de lo divino. Ahora bien, Lutero insistió con violencia sobre la inutilidad de la especulación filosófica para conocer a Dios. Él hace estallar la contradicción: "El hombre no puede naturalmente querer que Dios sea Dios; por el contrario, él quisiera ser Dios y que Dios no sea Dios" (Disputatio contra scholasticam theologiam, tesis 17, I, $225,1)$. Al otro extremo de la modernidad, Nietzsche (IV, 1980, p.110), como buen luterano, extrajo las últimas consecuencias de esta proposición: "Si existieran dioses, ¿cómo soportaría yo no ser uno de ellos? No hay pues dioses”. No le queda al hombre más que crear, o ídolos o una suprafigura del hombre: "Un dios, ¿podrían ustedes crearlo? [...] Pero crear el superhombre, ustedes serían muy capaces". Con la posición luterana, el estatuto de la filosofía es durablemente modificado en el edificio del saber. Pero con Lutero, ella ocupará un lugar en numerosas universidades europeas.

Sin embargo, esta novedad tiene muchas fuentes, en toda la teología del siglo XIV y especialmente en el nominalismo: Ockham no cesa de repetir que "Dios no debe nada a nadie". Pero, por supuesto, ese primado de la gracia, y precisamente esa fórmula, no son más que un regreso al pensamiento de Agustín más allá de la integración, la asimilación y la disolución del aristotelismo. La posición 
de Lutero aparece pues allí aún como el resultado del primado de la teología sobre la filosofía, es decir, de una episteme típicamente medieval.

Se podría, no obstante, para periodizar con simplicidad la historia de la filosofía teniendo en cuenta sus relaciones complejas con la teología, darle dos límites teológicos. Uno delimitaría entonces el pensamiento medieval como aquel que corre entre el nacimiento del Islam, en el que la filosofía debe dialogar con las tres racionalidades teológicas (judía, cristiana y árabe), y el nacimiento del protestantismo. En efecto, a partir de esa época el pensamiento cristiano se divide, una división no resuelta por el principio de autoridad. El pensamiento filosófico y religioso es entonces parcialmente enfeudado a los diversos poderes políticos nacionales (a nombre del príncipe cuius regio, eius religio). En fin, la confrontación con la alteridad se continúa bajo la forma del orientalismo (descubrimiento de las lenguas y las culturas de Oriente) y de la comparación etnográfica entre la cultura occidental y las culturas amerindias (de Vitoria a Montaigne). La cultura europea toma su rostro moderno (actual): ya no es universitas, sino que a la vez está dividida, es relativa a los otros y mundializada.

\section{3. ¿̇odernidad de la Edad Media?}

H. Blumenberg hace reposar la modernidad, principalmente, sobre tres conceptos, de los que traza admirablemente su genealogía: la secularización, la valorización de la curiosidad y el ideal de progreso siempre indefinido. ¿Son estos caracteres propiamente modernos?

\subsection{LA DIALÉCTICA DE LA SECULARIZACIÓN}

ES POR ELLO QUE LA MODERNIDAD (como esencia de los Tiempos Modernos) se mantiene siempre en una relación dialéctica con la Edad Media. La "secularización" designa este proceso. Si este término designa, en primer lugar, la expropiación de los bienes del clero, aplicado a los problemas intelectuales, designa a su vez el proceso por el cual los Tiempos Modernos no habrían cesado de entregar al hombre lo que había constituido en primer lugar los bienes del clero.

Ahora bien, no es para nada seguro que tal concepto permita la emancipación fuera de la teología, perseguida por aquellos que lo aplican a la filosofía. La secularización siempre puede invertirse. Jamás faltarán pensadores e historiadores 
para recordar que tal concepto, que ha sido laicizado (por ejemplo los "derechos humanos"), pertenece originariamente y en derecho a la teología. ¿La pretensión de ofrecer al pensamiento y a la acción unos fundamentos nuevos y racionales no está comprometida, si se muestra que el contenido esencial de las representaciones modernas no es nada más que un conjunto de herencias judeo-cristianos secularizadas? Y, recíprocamente, si la razón debe extenderse a todas las dimensiones de la existencia humana (comprendidas la vida y la sensibilidad), ¿̇no está ella socavando sus propios fundamentos y haciendo imposible el proyecto de una plena racionalización de la vida? Tal es la dialéctica de la Ilustración que enunciaron Adorno y Horkheimer (1947): llevado a su término, el proyecto de la Ilustración se invierte como romanticismo. Así, la secularización siempre puede ser "invertida" ("retournée") por el cristianismo, dando a los conceptos filosóficos el lugar que ocupan o deberían ocupar en una teología por fin digna de su esencia y concentrada en lo que ella tiene de más propio. Es lo que específicamente se dio a la tarea de pensar un teólogo como Voegelin, pero puede decirse que toda la teología del siglo XX trabajó más o menos conscientemente sobre esa problemática.

El historiador de la filosofía encuentra igualmente esa dificultad. Por ejemplo, la metafísica, desde Duns Escoto, insiste cada vez más sobre la autonomía de las esencias, que tienen su consistencia por ellas mismas, en virtud de su no-contradicción y que no son producidas por una decisión divina (Bardout \& Boulnois, 2002). En el siglo XVI, un teólogo como Vázquez admite que estas esencias conservarían la misma consistencia incluso si Dios no existiera o no fuera su creador todopoderoso. Dios solo es, en cierto modo, su espectador. Una primera lectura podría ver en ese movimiento de salida de las esencias fuera de la esencia divina una suerte de laicización, pues la constitución de las esencias escaparía a Dios mismo. La dificultad proviene del hecho de que ella es operada por los teólogos más ilustres de la época y no por los filósofos: Descartes sostiene precisamente lo contrario, la creación de las verdades eternas. Es, pues, más coherente ver en este movimiento una "deteologización" operada por los mismos teólogos, con el fin de abandonar las representaciones que no serían dignas de Dios en su absoluta trascendencia. Por tanto, en nombre de la teología, la filosofía (y precisamente la lógica) se autonomiza. ¡Lejos de leer en la historia una secularización, nosotros leemos una emancipación de la razón exigida por la racionalidad teológica misma! 
En su concepto mismo, hay que recordar que la dialéctica de la secularización reposa sobre una paradoja. Pues es la Edad Media (occidental) la que inventó una teoría y una práctica de la secularidad, separando, en su teoría de las "dos espadas", el poder temporal del poder espiritual (de una manera muy diferente de la "sinfonía de poderes" en obra en el Imperio Bizantino). La secularización, al dirigir contra la Edad Media una de sus más grandes invenciones, no podrá jamás pagarle su deuda infinita, puesto que le debe su esencia y su existencia misma.

Además, al legitimar el concepto de secularización, Blumenberg habla del fin de la Edad Media como de un absolutismo teológico. Ahora bien, si es verdad que hay una acentuación de la teología de la omnipotencia en el siglo XIV, jamás llega al punto de negar la racionalidad y la bondad divinas. En efecto, Duns Escoto y Ockham insisten en el hecho de que Dios no puede hacer cosas contradictorias (y por lo tanto, que mantiene el principio de contradicción), y que no puede producir actos desordenados (Beckmann, 1994). Para ellos, ni el principio de racionalidad, ni el principio de la bondad divina son puestos en tela de juicio por la Edad Media, incluso por la más teológica. La filosofía moderna (pensemos en Leibniz) no invierte estos principios, los mantiene. Están pues presentes de Abelardo a Leibniz. Pero, reconozcamos que existe una vena inversa, más rara, de fines del siglo XIV y del siglo XV, que afirma que Dios puede engañarnos. Solo hay que recordar que la hipótesis del Dios engañador, una de las más puras tentativas de sumisión de la evidencia y de la certeza natural a la teología de la omnipotencia, o a la omnipotencia de la teología, es por excelencia la obertura de la meditación cartesiana, pretendidamente moderna, y que ella sigue siendo su condición de posibilidad.

\subsection{LA CURIOSIDAD Y EL DESEO DE SABER}

Para H. Blumenberg, el proyecto cartesiano de devenir "dueño y señor de la naturaleza” (Discurso del método, VI; Adam-Tannery, VII, p. 62) es moderno, es decir (extendiendo la intención más allá del contexto técnico y médico del proyecto cartesiano), el dominio de la naturaleza obtenido por una ciencia matematizada aplicada a su objeto por una técnica rigurosa. Blumenberg insiste entonces en la idea de que durante la Edad Media la ciencia jamás es buscada por ella misma. Tal actitud es casi unánimemente condenada bajo el nombre de "vana curiosidad". 
Sin embargo, no olvidemos que lo que condena la Edad Media es la curiosidad vana, la que busca elementos de la ciencia, sin que ellos puedan acercar a Dios, la que dispersa en lo múltiple en lugar de conducir hacia la unidad. Inversamente, el elogio del estudio, de la investigación intelectual, es frecuente. Hugo de San Víctor, hacia 1140, considera que todos los hombres tienen el deber de estudiar.

Muchos (...) comprometidos más de lo necesario en los asuntos y los problemas de este mundo, o entregados a los vicios y a los placeres de los sentidos, esconden bajo tierra el talento de Dios y no buscan extraer de él ni el provecho de la sabiduría ni el beneficio de una obra buena. (...) Para otros, es la falta de fortuna personal o la modestia de los ingresos los que reducen su capacidad de instruirse. No creemos, sin embargo, que puedan ser excusados completamente, puesto que vemos a otros que alcanzan el fruto de la ciencia sufriendo de hambre, de sed, de desnudez. (Didascalion, prefacio, 1991, p. 62)

Hugo hace del rechazo de estudiar una falta tal que, ninguna situación social o personal, por difícil que sea, pueda excusar a los hombres. En la misma obra concluye: "No menosprecies ninguna ciencia, pues toda ciencia es buena. (...) El estudiante avisado (...) no desprecia ningún escrito, ninguna persona, ninguna enseñanza" (Didascalion, 1991, p. 146).

Ciertamente, sería anacrónico buscar un elogio de las ciencias experimentales (salvo bajo la pluma de Roger Bacon) antes del siglo XVII. Pero la actitud intelectual de búsqueda es netamente valorizada por los teólogos medievales, en la medida en que se piensa que toda ciencia orientada hacia su principio acerca a Dios y permite conocerlo mejor.

\subsection{LA CONCEPCIÓN DEL PROGRESO}

UNA DE LAS REIVINDICACIONES PRINCIPALES de la modernidad es la de haber tenido el monopolio de la conciencia del progreso. Blumenberg piensa que esta conciencia se afirma con Pascal, proclamando en el Esprit de géométrie que la humanidad en general progresa de la misma manera que un hombre que pasa de la infancia a la edad adulta. Frente a esto, el cristianismo medieval solo habría conocido una tensión entre la escatología (es decir, el rechazo del tiempo del mundo) y la secularización en un tiempo igual, no orientado hacia el progreso, incluso progresivamente decadente a medida que se aleja del origen. 
Ahora bien, tal idea del progreso no es en absoluto una invención moderna. La Edad Media conoce ciertamente algunas reflexiones sobre la decrepitud del mundo, lo que puede conciliarse por otra parte, con lo que decía Aristóteles en el De Caelo (I, 2, 269a 19-20): "lo perfecto es anterior a lo imperfecto"; o en la Politica (II, 5, 1264a 3): "casi todo ya ha sido descubierto". Pero sobre esta trama más bien literaria y filosófica, la Edad Media también conoció teologías de la historia en las que la humanidad se aproxima por escalones a su fin último (Joaquín de Fiore, Buenaventura, los franciscanos espirituales del siglo XIII) (Ratzinger, 1959; Burr, 1976). Incluso la célebre fórmula de Bernardo de Chartres: "somos enanos subidos en los hombros de gigantes" (Jean de Salisbury, Metalogicon III, 4, p. 116), si implica una crítica de los individuos más recientes, es una afirmación del progreso de la humanidad: a pesar de nuestra debilidad, vemos más lejos que los antiguos.

Pero, es sobre todo en los más filósofos de los teólogos que esta conciencia es aguda. La encontramos incluso regularmente en santo Tomás. Señalemos por ejemplo el Prólogo de su Comentario a Job:

Así como, para las cosas que son engendradas naturalmente, se llega poco a poco de lo imperfecto a lo perfecto, así mismo los hombres llegan al conocimiento de la verdad. En efecto, al comienzo, ellos alcanzan una pequeña porción de la verdad, pero enseguida, paso a paso, alcanzan una medida más completa de la verdad. Por ello, al comienzo, debido a un conocimiento imperfecto, muchos hombres se encuentran en el error con respecto a la verdad. Entre ellos, algunos, al excluir la divina providencia, atribuyen todo a la fortuna y al azar. [...] Sin embargo, el celo de los filósofos ulteriores, que buscaban la verdad de manera más perspicaz, mostró, por indicios y razones evidentes, que la naturaleza era movida por la providencia. (Opera Omnia XXVI, 1965, p. 3; texto comentado por Dahan, 2003)

Se observará justamente que, a propósito de un problema que se encuentra en el cruce de la filosofía y la teología, como el de la Providencia, santo Tomás no recurre a la autoridad revelada. La fuente del progreso se encuentra, toda entera, en la perspicacia de la razón humana, que progresa poco a poco en el descubrimiento de la verdad. Es pues en el plano filosófico de la razón que puede encontrarse un progreso de la humanidad. Y puede encontrarse en santo Tomás, a propósito de otros numerosos problemas, una conciencia aguda de la evolución histórica y del progreso de la filosofía. 
Como lo afirma Umberto Eco (1997), la cultura medieval da "la impresión de no expresar jamás nada nuevo. Pero esto es falso, pues la cultura medieval posee un sentido de la innovación; pero ella se desvela por disimularlo bajo los oropeles de la repetición (redite) (a diferencia de la cultura moderna que simula renovar cuando no hace más que repetir)" (p. 12). La paradoja de toda teoría de la modernidad es doble: $1^{\circ}$ ) si la modernidad nace de una crisis de civilización, puede decirse que ella hace de la crisis y de la evolución un valor, lo que es contradictorio: al quererse regla de evolución de toda sociedad, ella se vuelve a su vez una tradición. $2^{\circ}$ ) Siempre puede encontrarse la fuente de ello en la Edad Media. La ruptura parece una abstracción construida por los historiadores sobre un fondo histórico continuo. La Edad Media se presenta entonces como la matriz del progreso histórico, un período de acumulación progresiva de un capital que será en seguida mundializado. Le Goff habla así de una "larga Edad Media", que va hasta el siglo XVII. A. Boureau (2002), por su parte, ve en la Edad Media "el período de gestación y de construcción de la Europa conquistadora, cuna de la producción industrial y de los intercambios generalizados" (pp. 950-953). El concepto de Edad Media es solidario de una visión europeocéntrica de la historia. Ahora bien, es verdad que desde el punto de vista cuantitativo, ningún otro período, ninguna otra sociedad ha acumulado paulatinamente tantos progresos intelectuales, técnicos y económicos, como los que van a expandirse por el mundo entero con el descubrimiento de América: progreso de la agricultura, dominio de la energía animal, mano de obra asalariada, urbanización, nacimiento de las universidades, del Estado, del derecho. Sin embargo, la Edad Media, en tanto que entidad cultural, no se reduce a sus propios límites espaciales ni temporales. Espaciales: sin un diálogo e interacción permanentes con las culturas árabe, judía y bizantina, no habría sido ella misma. Temporales: la Edad Media no cesa de alimentarse del tiempo discontinuo de la Antigüedad, recuperada por migajas, perdida por eclipses, redescubierta por fragmentos.

Que se trate de secularización, curiosidad o progreso, desde la Edad Media encontramos los indicios del "despegue" intelectual de Occidente. En consecuencia, si la Edad Media y los Tiempos Modernos son correlativos, es porque el ideal medieval ya era, en sus empresas intelectuales (es decir, reconozcámoslo, para una pequeña élite urbana) moderno. Pero, entonces, si hay una modernidad de la Edad Media, ¿el concepto de modernidad no pierde toda validez? 


\section{Postmodernos y premodernos: ¿quién es nuestro contemporáneo?}

PODRÍAMOS LIMITARNOS A ALGUNAS PRECISIONES HISTORIOGRÁFICAS que reequilibrarían la balanza entre la Edad Media y la Modernidad. Podríamos limitarnos a ver en la Edad Media indicios de la Modernidad, y en la Modernidad una deuda hacia la Edad Media. Pero eso sería muy pobre. Hay que examinar los presupuestos en juego en tal interpretación. Hay también que preguntarse si un pensamiento gana más siendo un pensamiento de su tiempo o siendo intempestivo.

\section{1 ¿QUIÉN ES RACIONAL?}

EL PRIMER PRESUPUESTO CONSISTE EN LA BÚSQUEDA de un origen mítico. No importa el ángulo desde le cual se estudia la Edad Media, todo depende del lugar con respecto al cual se sitúa la continuidad temporal. Todos los orígenes son hechos para ser perdidos. En consecuencia, todo depende del punto en el que se sitúe el origen: si se dice que el cristianismo es el origen absoluto, estamos seguros que él se alejará. Partir del cristianismo medieval es, pues, inconscientemente, endosar una escala temporal que conducirá automáticamente a la secularización.

Pero, a sus propios ojos, el cristianismo no es el origen: desde san Pablo, él se refiere a una doble fuente, el judaísmo y el helenismo (Brague, 1993). Por esencia, él es segundo. Contrariamente al Islam (para el que la verdadera religión de Abraham solo es develada en el Corán), el cristianismo no busca en absoluto descalificar a sus predecesores como falsificaciones. De allí, el mito patrístico y medieval según el cual Platón habría tenido algún conocimiento de la sabiduría judía, para fundar una armonización de las sabidurías. Para el cristianismo, el advenimiento de Cristo es el medio y el centro de la historia, él no es ni su término ni su origen. De otro lado, esto explica su sistema de datación. Los otros sistemas, a partir de la fundación de Atenas, de Roma, o de la creación del mundo (para el judaísmo), parten de un origen inalcanzable y siempre incierto (Maier, 2002) ${ }^{5}$. Solamente el

5 La datación a partir de la Hégira también se hace a partir de un punto identificable, pero su estatuto es diferente: mientras que el Nuevo Testamento cumple con la promesa del Antiguo Testamento, la revelación pre-islámica en el Islam es considerada como una falsificación con respecto a la revelación de Mahoma. 
integrismo cree que el cristianismo es todo y que no hay otro comienzo que él mismo.

Considerado en su diferencia frente al judaísmo y al paganismo, el cristianismo aparece como un momento diferente de la historia humana, que se inserta en una cultura y una ética preexistentes, pero que él modifica sustancialmente. Vayamos más lejos: este encuentro no es lo propio de la Edad Media, este se consumó mucho antes en la antigüedad cristiana, por los Padres de la Iglesia. Lo que caracteriza la Edad Media es la confrontación con otras racionalidades monoteístas (el Islam), el uso esencial de la lógica, que conduce a la existencia de una teología como ciencia, dialogando y disputando con la filosofía. Esta doble disociación: de la filosofía frente a la teología cristiana y de la teología cristiana frente al pensamiento árabe y judío, es característica de la Edad Media como régimen de múltiples racionalidades.

Incluso si uno es sensible a los supuestos de toda historia europeocéntrica, no parece necesario abandonar el concepto de Edad Media. La legitimidad de este período consistió, en efecto, en considerar todas las racionalidades, sin negar, no obstante, la dimensión profundamente religiosa del hombre. La confrontación del cristianismo y de las racionalidades no es un juego de suma cero, en el que todo lo que enriquece a uno es automáticamente retirado del otro.

\section{2 ¿DÓNDE ESTÁ EL SENTIDO?}

EL SEGUNDO PRESUPUESTO CONSISTE EN NUESTRA ACTITUd frente a nosotros mismos, observadores contemporáneos. En el dominio de la filosofía sería inútil y vano el enfrentar la Edad Media contra la Modernidad. Esto sería simplemente desplazar hacia otro objeto la actitud "moderna". Querer a como dé lugar “modernizar" la Edad Media es suponer aún que la Modernidad es la medida de todas las cosas. Pues el concepto de Modernidad supone siempre un cumplimiento de la verdad en una época antes que en otra. Implica una historia finalística, orientada hacia un progreso. Pero nada prueba que lo que es cuantitativamente indiscutible en la historia de la civilización europea se verifique en el dominio del pensamiento (teología, filosofía, lógica, estética, ética). Y, en ese caso, ¿por qué privilegiar un período antes que otro?

La única actitud prudente aquí consiste en distinguir y ordenar las preguntas. Si se entiende por Edad Media lo que nos separa, lo que recubre de oscuridad, 
ignorancia y olvido los debates verdaderos, la lucha contra esa Edad Media una Edad Media que ya no es un período histórico, sino el reveso de nuestra memoria selectiva - es una dimensión necesaria de todo pensamiento. E, inversamente, lo actual no es necesariamente lo moderno. Hay problemáticas "contemporáneas" que nos disimulan los verdaderos debates.

Una relación abierta al mundo contemporáneo no puede tener lugar si no se busca la genealogía de los "olvidos" que caracterizan nuestra época. Las consideraciones inactuales son sin duda más esenciales y más urgentes para liberar al pensamiento de su lastre que las respuestas a los falsos debates contemporáneos.

En esta genealogía, todo trabajo histórico serio implica una periodización propia de su objeto. Por ejemplo, en su trilogía sobre el problema de los universales, Alain de Libera sostuvo que, sobre este punto, la Edad Media comienza en el siglo VI y termina en el siglo XIX. La pregunta moderna del empirismo recubrió la pregunta metafísica y lógica de los universales. "El nominalismo medieval, al menos el de Ockham, no es una filosofía de la semejanza, ni su teoría de los universales una anticipación del empirismo clásico". Y también: "la pregunta de los universales que trata de elaborar Ockham no es la de Locke" (de Libera, 1998, pp. 19 , 448). La pregunta solo será replanteada en el siglo XIX por los lógicos y metafísicos como Bolzano, Meinong y Frege. Esto implica que el pensamiento "moderno" amerita el estatuto de nueva Edad Media, en el sentido en que interrumpe una tradición de recepción y de renacimiento del problema heredado de la Antigüedad. Estamos pues llamados a una transformación historiográfica.

Yo mismo sostuve que la estructura de la metafísica moderna, la que domina de Suárez a Kant, había sido elaborada por el pensamiento medieval a comienzos del siglo XIV, alrededor de la obra de Duns Escoto.

Puede también estimarse que la estética moderna, al interpretar la representación asegurada por la obra de arte como una exactitud absoluta, rompe, alrededor de los siglos XV y XVI, con la estética medieval, ocultando la problemática no representativa del arte, que no será reencontrada hasta comienzos del siglo $\mathrm{XX}$. Así, si se interroga desde el punto de vista de las teorías de la imagen, en estética, la Edad Media es más moderna de lo que se afirma, y la Edad oscura se extiende de los siglos XVII a XIX. 


\section{3 ¿QUIÉN ES MI CONTEMPORÁNEO?}

¿QUiÉn ES MI CONTEMPORÁNEO? SE ME PERMitiRá observar que esta pregunta evoca la pregunta del Evangelio: ¿quién es mi prójimo? Ahora bien, conocemos la parábola del samaritano, que responde a esa pregunta: el prójimo no es aquél que se me asemeja y del que soy cercano, sino el extranjero y el lejano del que me hago próximo. Por analogía, nuestro contemporáneo no es el presente y el próximo que se impone a nosotros, sino el lejano y diferente del cual mi pensamiento va a enriquecerse. ¿Cuándo somos verdaderamente contemporáneos de algo? ¿Y, de qué? El privilegio del historiador y del filósofo consiste en elegir sus contemporáneos entre los "grandes transparentes"; pues dialogando con ellos, deja de ser un extranjero para ellos.

Digámoslo de otro modo: nadie es obligado a ser contemporáneo de otro; cada uno es libre de escoger sus contemporáneos.

Una de las grandes mutaciones de la filosofía contemporánea se funda en el hecho de que redescubre actualmente la dimensión filosófica de la Edad Media. Esta deja de presentarse como una época sombría, no solo en el dominio social y estético, sino sobre todo en el dominio conceptual. En todos los dominios de la reflexión filosófica, en los que uno se esfuerza en pensar preguntas concretas, acerca de singularidades, hay que utilizar con sumo cuidado los universales historiográficos que constituyen esos términos cómodos, pero problemáticos como "Edad Media” y “Tiempos Modernos". La historia no es teleológica. Hay desplazamientos y retornos que no son integrables en un sentido de la historia. Los universales históricos no existen, son las prácticas singulares las que los hacen existir.

Esta situación, sin duda, tiene que ver con la situación actual de la filosofía, llamada "posmoderna". Más allá de lo que se entienda por ese término vago, él significa claramente el abandono de los modelos "modernos" y del ideal moderno. Solo puede llegar a pensarse su legitimidad abandonando los prejuicios inherentes a la teoría de la modernidad. Solamente una Edad Media estudiada por ella misma, antes que como origen de los Tiempos Modernos, es decir, sin modernidad, puede ser resueltamente contemporánea.

¿La interpretación que he desarrollado es el signo de un relativismo o de un subjetivismo puro? De ningún modo. No rechazo la idea de que hay verdades, e incluso principios universales, objetivos y racionales. Admito, igualmente, que se 
expresan en la historia. Concedo incluso que se llame "moderno" a todo pensamiento en el que percibamos un desarrollo (essor) de la racionalidad. Sin embargo, simplemente creo que la historia del reconocimiento de estas verdades no puede ser contada como la de un progreso continuo y universal. Creo que en historia de la filosofía hay que abandonar las maquinaciones finalísticas; que al filósofo aún le corresponde establecer, para cada concepto racional, la manera como poco a poco fue construido, lo que implica una periodización correlativa a la problemática que le da sentido. Es un trabajo largo y paciente, más difícil que aplicar un esquema histórico, pero es un trabajo necesario.

En efecto, la modernidad se construyó contra la Edad Media. Y, sin embargo, hoy sabemos que aquella no habría podido ser posible sin esta. El filósofo sabe hoy que los filósofos modernos de la conciencia, lejos de destronar la metafísica medieval, se apoyan de hecho sobre estructuras metafísicas elaboradas en la Edad Media. Al estudiar la Edad Media, estudiamos pues $1^{\circ}$ ) la cara oculta de nuestra historia, lo reprimido que siempre nos ha sido ocultado por la historiografía dominante; $2^{\circ}$ ) lo que hace posible la misma modernidad. De golpe, podemos tener una relación más libre con el pensamiento, pues se trata de una relación crítica con respecto a los cuadros y conceptos tradicionales. ¿Qué nos ofrece la filosofía medieval que haya sido ocultado por la filosofía moderna? Una atención particular al lenguaje, puesto que, después de Aristóteles, todos los autores medievales estiman que la filosofía reposa sobre las artes del lenguaje, que toda tesis filosófica pertenece a una teoría de los enunciados. Al remontar más acá de las filosofías de la conciencia, reencontramos uno de las grandes preocupaciones de la filosofía analítica: considerar el pensamiento como un sistema de juegos del lenguaje. Estudiar la Edad Media no consiste pues en dedicarse simplemente a consideraciones inactuales, es darse los medios para superar la crisis de los conceptos fundamentales de la modernidad, la crisis de la misma filosofía contemporánea.

Comenzamos preguntándonos: “Qué significa pensar?" Ahora podemos hacer esta otra pregunta que quizá sea sinónima: “QQué libera el pensamiento?” Ahora podemos responder: la Edad Media. La filosofía medieval nos parece hoy más que nunca esencial, porque nos libera de la tiranía del presente.

Platón es aún hoy nuevo; Pico de la Mirandola, también. Y no son menos nuevos Ockham o el Maestro Eckhart. Lo son de otro modo. 


\section{FUENTES PRIMARIAS}

Averroes. (1572). Aristotelis Opera cum Averrois Commentaria. vol. IV, De Physico auditu. Venecia: ed. des Juntes.

Beaudelaire, Ch. (1976). CEuvres complètes. Tome II. Cl. Pichois (Ed.), Bibliothèque de la Pléiade. Paris: Gallimard.

Chateaubriand, F.-R. (1860). Mémoires d'outre-tombe. Tome V. Paris: Dufour, Mulat et Boulanger éditeurs.

Descartes, R. (1996). Discours de la méthode. Adam-Tanney (Eds.), CEuvres de Descartes. Tome VII. Paris: Vrin.

Francesco Pétrarque. (2000). Sur mon ignorance et sur tant d'autres choses. (Ed. y Trad. C. Carraud). Grenoble: Jérôme Millon.

Hegel, G.W.F. (1954). Leģons sur l'histoire de la philosophie. (Trad. G. Gibelin). Paris: Gallimard.

Hugo de San Víctor. (1991). Didascalicon, L'Art de lire. (Trad. fr. M. Lemoine). Paris: Cerf.

Juan de Salisbury. (1991). Metalogicon. J.B. Hall, \& K.S.B. Keats-Rohan (Eds.). Turnhout: Brepols.

Lutero, M. (1517). Disputatio contra scholasticam theologiam. Weimarer Ausgabe WA 1 Schriften 1512/18 (einschließlich Predigten, Disputationen). Weimar. Nietzsche, F. (1980). Also Sprach Zarathoustra. Werke. Kritische Gesamtausgabe IV. G. Colli \& F. Montinari (Eds.). Berlin-Nueva York: Gruyter.

Pico de la Mirandola. (1993). CEuvres philosophiques. (Trad. y notes O. Boulnois \& G. Tognon). Paris: Presses Universitaires de France.

Renan, E. (1949). Oeuvres complètes. Tome III. H. Psichari (Ed.). Paris: CalmannLévi.

Spinoza B. (1925). Ethica. Spinoza Opera. Tome II. C. Gebhardt (Ed.). Heidelberg: Carl Winters.

Tomás de Aquino. (1965). Expositio super Iob ad litteram. Opera omnia XXVI. A. Dondaine (Ed.). Ciudad del Vaticano: Typis Polyglottis. 


\section{FUENTES SECUNDARIAS}

Adorno, T.W. \& Horkeimer, M. (1947). Dialektik der Aufklärung. Philosophische Fragmente. Amsterdam: Querido.

Bardout, J.-C. \& Boulnois, O. (Dir.) (2002). Sur la Science divine. Paris: Presses Universitaires de France.

Beckmann, J.P. (1994). 'Nihil notum nisi complexum'. Von der Sach- zur Satzwissenschaft am Beispiel der Metaphysik. I. Craemer-Ruegenberg \& A. Speer (Dirs.), Scientia und Ars im Hochmittelalter und Spätmittelalter (pp. 266-280). Vol. I. Berlín-Nueva York: Gruyter.

Bianchi, L. \& Randi, E. (1993). Vérités dissonantes. Aristote à la fin du Moyen Age. Friburgo (Suiza)-Paris: Editions Universitaires-Le Cerf.

Blumenberg, H. (1988). Die Legitimität der Neuzeit. Francfort: Suhrkamp.

Boulnois, O. (1993). Humanisme et dignité de l'homme selon Pic de la Mirandole. Postfacio a Pic de la Mirandole. Oeuvres philosophiques (pp. 293-323). Paris: Presses Universitaires de France.

Boulnois, O. (2000). Scolastique et humanisme, Pétrarque et la croisée des ignorances. Prefacio a Petrarca. C. Carraud (Ed. y Trad), Sur mon ignorance et sur tant d'autres choses (pp. 5-43). Grenoble: Jérôme Millon.

Boureau, A. (2002). Moyen Age. C. Gauvard, A. de Libera \& M. Zink (Dirs.), Dictionnaire du Moyen Age (pp. 950-953). Paris: Presses Universitaires de France.

Brague, R. (1993). Europe, La Voie romaine. Paris: Critérion.

Burr, D. (1976). The Persecution of Peter Olivi. Philadelphia (USA): The American Philosophical Society.

Charles, D. (1996). Esthétique. Encyclopaedia Universalis. Tome VIII. Paris.

Dahan, G. (2003). Ex imperfecto ad perfectum. Le progrès de la pensée humaine chez les théologiens du XIIIe siècle. E. Baumgartner \& L. Harf-Lancner (Dirs.), Progrés, réaction, décadence dans l'Occident médiéval (pp. 171-184). Génova: Droz.

Eco, U. (1997). Art et Beauté dans l'esthétique médiévale. París: Grasset. 
Faye, E. (2002). Dignité de l'homme (Philosophie). C. Gauvard, A. de Libera \& M. Zink (Dirs.), Dictionnaire du Moyen Age (pp. 418-419). Paris: Presses Universitaires de France.

Garin, E. (1938). La dignitas hominis e la letteratura patristica. La Rinascita, 1 , pp. 102-146.

Ladner, G.H. (1982). Terms and Ideas of Renewal. R.L. Benson \& G. Constable (Eds.), Renaissance and Renewal in the Twelfth Century (pp. 1-33). Cambridge, Mass.: Harvard University Press.

Libera, A. de. (1993). La Philosophie Médiévale. Paris: Presses Universitaires de France.

Libera, A. de. (1998). La Querelle des Universaux. Paris: Seuil.

Lubac, H. de. (1974). Pic de la Mirandole, Études et discussions. Paris: Aubier Montaigne.

Maier, H. (2002). La chronologie chrétienne, un temps dans le temps ? C. Michon (Dir.), Christianisme, Héritages et destins (pp. 47-81). Actes du colloque « 2000 ans aprés quoi ? ». Paris: Le livre de poche.

Nadler, S. (2002). Spinoza's Heresy: Immorality and the Jewish Mind. New York: Oxford University Press.

Quinto, R. (2001). Scholastica, Storia di un Concetto. Padua: Il Poligrafo.

Ratzinger, J. (1959). Die Geschichtstheologie des heiliges Bonaventuras, Múnich: Schnell \& Steiner.

Schmutz, J. (2000). Bulletin de scolastique moderne (I). Revue Thomiste, 2, pp. 270-341.

Wolfson, A.-H. (1936). The Philosophy of Spinoza. Cambridge (Mass.): Harvard University Press. 